\title{
Artigos
}

Iann Endo Lobo ${ }^{1}$

Igor Campos da Silva

\section{AS BASES DA CIÊNCIA SOCIAL WEBERIANA E A INTERPRETAÇÃO CRÍTICA DE LEO STRAUSS}

\author{
THE FOUNDATIONS OF WEBERIAN SOCIAL SCIENCE AND LEO \\ STRAUSS'S CRITICAL INTERPRETATION
}

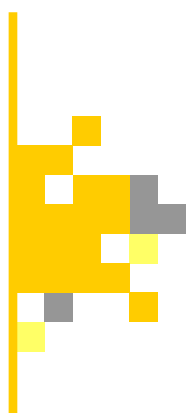

\section{RESUMO:}

O presente trabalho tem como objetivo analisar os postulados que fundamentam a ciência social eticamente neutra proposta por Max Weber, a partir da leitura crítica de Leo Strauss. Na primeira sessão, procuramos expor os argumentos metodológicos e epistemológicos do cientista social alemão, tais como a objetividade do conhecimento, a "neutralidade axiológica", a distinção entre fatos e valores e a negação de que, ancorados na razão e na ciência, possamos realizar julgamentos objetivos sobre os valores últimos. Na sessão seguinte, apresentamos a interpretação crítica que o filósofo político Leo Strauss faz sobre as bases da ciência social weberiana e os supostos relativismo e niilismo subjacentes a ela. Nas considerações finais, refletimos sobre a possibilidade, apresentada por Strauss e defendida por Nasser Behnegar, de fundamentar uma ciência social que ultrapasse os limites autoimpostos sem tornar-se dogmática ou submeter-se ao pensamento religioso.

Palavras-chave: Max Weber; Neutralidade Axiológica; Direito Natural; Valores; Niilismo.

\section{ABSTRACT:}

The present work aims to analyze the postulates that support the ethically neutral social science proposed by Max Weber, through Leo Strauss's critical perspective. In the first session we tried to present the methodological and epistemological arguments of the German social scientist, such as the objectivity of knowledge, the "axiological neutrality", the distinction between facts and values and the denial that, anchored in reason and science, we can make judgments objectives on the ultimate values. In the following section, we present the critical interpretation that political philosopher Leo Strauss makes about the foundations of Weberian social science and the supposed relativism and nihilism underlying it. In the final remarks, we raise the reflection upon the possibility, presented by Strauss and defended by Nasser Behnegar, of founding a social science that goes beyond self-imposed limits without becoming dogmatic or submitting to religious thought.

Keywords: Max Weber; Axiological neutrality; Natural Law; Values; Nihilism.

\section{INTRODUÇÃO}

Max Weber (1864 - 1920) foi um autor fundamental para a constituição das Ciências Sociais. Parte importante da obra weberiana refere-se às reflexões epistemológicas em que o autor se dedicou aos problemas básicos da disciplina, tais como a objetividade do conhecimento, a "neutralidade axiológica" e a distinção entre fatos e valores. Con- siderado por muitos o maior cientista social do século XX, Weber foi o herói de uma geração e continua exercendo importante autoridade sobre o campo, suas reflexões mostram-se relevantes até os dias de hoje. Leo Strauss (1899 - 1973), por sua vez, foi um filósofo político teuto-americano de origem judaica que se dedicou ao estudo da histó-

\footnotetext{
${ }_{1}^{1}$ Doutorando em Sociologia e Ciência Política (UFSC) - iannloboe@gmail.com iD https://orcid.org/0000-0001-7567-1894

${ }^{2}$ Mestrando em Sociologia Política (UFSC) - igor.campos.sc@gmail.com (iD https://orcid.org/0000-0002-3994-8187
} 
ria das ideias políticas desde os clássicos até seus contemporâneos. Sua formação na Alemanha do início do século $X X$ possibilitou o contato com o neokantismo, o movimento sionista e os elementos daquilo que ele chamou de "niilismo alemão" ${ }^{3}$. Após sua formação na Alemanha, refugiado, Strauss passou a maior e mais importante fase de sua carreira no departamento de Ciência Política da Universidade de Chicago nos Estados Unidos onde, imune à ciência social positivista dominante, publicou em 1952 "Natural Right and History", resultado de uma série de conferências feitas durante 1949 sobre a temática do direito natural ${ }^{5}$, a obra é considerada por muitos o seu trabalho mais influente. Strauss dedicou o segundo capítulo do livro, intitulado "O direito natural e a distinção entre fatos e valores" à interpretação crítica da obra de Max Weber", considerado por ele "o maior cientista social de nosso século" (STRAUSS, 2014, p. 45).

A herança do pensamento weberiano é plural, vasta e se estende as mais diversas áreas da filosofia e das ciências humanas. Um dos problemas centrais do pensamento de Weber foi a questão dos valores (Werte), desde uma perspectiva epistemológica e metodológica, na qual a relação com valores, segundo o sociólogo, era de suma importância para a construção da pesquisa social, até uma perspectiva ética política, na qual os valores aparecem como um problema, dentro do contexto pós marxista e pós nietzschiano de Weber. Pretendemos contribuir para a discussão dessa problemática a partir da análise da crítica straussiana ao suposto niilismo implicado na filosofia dos valores weberiano, que apesar de muito relevante, ainda é pouco debatida nos meios acadêmicos brasileiros.
A discussão que abaixo se segue está dividida em três seções. Na primeira, procuramos analisar as bases que fundamentam metodológica e epistemologicamente a ciência social proposta por Max Weber. Na segunda, investigamos a interpretação crítica dos postulados weberianos desenvolvida por Leo Strauss. Por fim, apresentamos de modo breve uma reflexão ancorada nas proposições de Strauss e Behnegar a respeito da possibilidade de uma nova ciência social "genuína", não dogmática e valorativa.

\section{MAX WEBER E A CIÊNCIA SOCIAL ÉTICAMENTE NEUTRA}

Os estudos metodológicos e epistemológicos de Weber estão concentrados na coletânea intitulada "Gesammelte Aufsätze zur Wissenschaftslehre", publicada em 1922, dois anos após a morte do autor, sob revisão de Johannes Winckelmann. No Brasil, a obra foi traduzida em duas partes com o título "Metodologia das Ciências Sociais" (1993) publicado pela editora Cortez/ Unicamp. É nela que se encontram textos importantes para nosso estudo, como "Die Objektivität sozialwissenschaftlicher und sozialpotischer Erkenntnis" (1904) traduzido por "A 'objetividade' do conhecimento na Ciência Social e na Ciência Política" e "Kritischen Studien auf dem Gebiet der kulturwissenschftlichen Logik" traduzido por "Estudos críticos sobre a lógica das ciências da cultura" (1906). Ambos publicados originalmente no importante periódico do qual Weber foi editor "Archiv für Sozialwissenschaft und Sozialpolitik". A célebre conferência "Wissenschaft Als Be-

\footnotetext{
${ }^{3}$ Representado, principalmente, por Nietzsche, Heidegger e Weber. Strauss oscila entre a crítica e a utilização instrumental dessas escolas na fase madura de sua obra, operação semelhante àquela feita por Platão em relação ao personagem Trasímaco n'A República. Disso decorre o caráter esotérico da crítica straussiana. Sobre esse ponto ver: (Strauss, 1964, p. 74; Behnegar, 1997, 104).

${ }^{4}$ Traduzido no Brasil por Bruno Simões e publicado pela editora Martins Fontes em 2014 sob o título "Direito Natural e História". Concentraremos nossa análise no segundo capítulo do livro somado a outras obras de Strauss e à interpretação de comentadores.

${ }^{5}$ Durante todo o livro, Strauss atenta para a necessidade de fundamentar filosoficamente o direito natural, afirmando que rejeitá-lo seria afirmar que todo direito é positivo e determinado exclusivamente pelos agentes jurídicos e legisladores. Sua preocupação é primeiro mostrar as inconsistências da rejeição moderna ao direito natural em nome da História e da Ciência Social baseada na distinção entre fatos e valores. Portanto, a obra tem como intuito limpar o caminho para uma possibilidade e não postular dogmaticamente o direito natural em si.

${ }^{6}$ Como observa Richard Kennington no artigo "Strauss's Natural Right and History" (1981), Weber é o único pensador do século XX a quem Strauss dedicou um capítulo inteiro do livro. O capítulo também é o único em que Strauss explora o problema "teológico-político", tema fundamental no restante de sua obra que aborda o conflito entre religião e filosofia ou "razão e revelação".
} 
ruf" (1967), traduzida para o português pela editora Cultrix sob o título "Ciência como Vocação" (2011) também fará parte do nosso referencial teórico.

Já na primeira parte do texto "A objetividade do conhecimento na Ciência Social e na Ciência Política", Weber e os demais autores ${ }^{7}$ destacam os limites das ciências empíricas ao insurgirem-se contra a tendência do cientista social em proferir juízos de valor, pois estes, derivam de "determinados ideais" tendo, portanto, "origens subjetivas" (WEBER, 1993, p. 109). Cabe a ciência "estabelecer quais meios seriam apropriados ou não aos determinados fins propostos", mas nunca "tomar uma determinada decisão em função daquelas ponderações" (Ibidem, p. 109-10). Segundo Weber, é possível oferecer uma crítica científica aos ideais e juízos de valor, mas a crítica limita-se à critérios lógicos e nada pode afirmar sobre o conteúdo. Aqui, o autor baseia-se na distinção rickertiana entre juízo de valor (Werturteil) e relação, ou referência, a valor (Wertbeziehung). A ciência deve permanecer no campo dos fatos, sem preferências ideológicas, especulações metafísicas ou tomadas de posição a respeito de valores últimos, essas são competências próprias da filosofia. Conforme argumenta Raquel Weiss ao interpretar nosso autor, o limite da ciência é apontar para as possíveis contradições e inconsistência, e a "abstenção de juízos de valor é condição sine qua non para garantir a objetividade do conhecimento científico" (WEISS, 2012, p. 122).

Se as Ciências Sociais têm como objeto os valores sem que possa emitir juízos sobre eles, de que forma é possível uma explicação objetiva? Weber dedica a segunda parte do texto para formular seu método baseado na utilização instrumental dos tipos ideias, esses que são úteis como meio para a pesquisa empírica, mas nunca como fim. O tipo ideal trata-se de um quadro do pensamento, não da realidade histórica ou "autêntica". Ele é um meio pelo qual devemos buscar dominar a realidade através da reflexão e da compreensão, uma utopia que não se encontra na natureza e presta-se à tentativa de apreender os indivíduos históricos e seus elementos em conceitos genéricos provisórios, dada a impossibilidade de descrever a realidade em sua totalidade. O tipo ideal difere radicalmente do "dever ser" ${ }^{8}$ exemplar, Weber deixa isso claro ao argumentar que seus exemplos vão dos prostíbulos às religiões. $O$ destino do tipo ideal é a transitoriedade, ele será sempre superado pelos próximos passos da ciência inacabada e constantemente aprimorada. Novos problemas trarão novos aprimoramentos e a necessidade de construção de novos tipos ideias.

Portanto, para Weber, não há como deduzir a realidade através de leis ou fatores gerais e imutáveis ${ }^{9}$. Os fenômenos históricos possuem uma individualidade, não incidem sobre leis abstratas, mas sobre conexões causais concretas. O autor distingue o trabalho teórico do trabalho histórico, criticando o que ele chama de "monismo naturalista" que pretende apreender um conhecimento da realidade livre de contingências e individualidades (Weber, 1993). No entanto, Weber expõe a sutileza da linha que separa a ciência da crença:

\begin{abstract}
A validade objetiva de todo saber empírico baseia-se única e exclusivamente na ordenação da realidade dada segundo categorias que são subjetivas, no sentido específico de representarem o pressuposto do nosso conhecimento e de associarem, ao pressuposto de que é valiosa, aquela verdade que só o conhecimento empírico nos pode proporcionar. Com os meios da nossa ciência, nada poderemos oferecer àquele que considere que essa verdade não tem valor, visto que a crença no valor da verdade científica é produto de determinadas culturas, e não um dado da natureza. (WEBER, 1993, p. 152).
\end{abstract}

Com a impossibilidade de apreensão do real em sua totalidade, em última instância, o conhecimento é orientado por ideias de valor. De acordo com Weber, a realidade é infinita, mas o conhecimento humano é finito, sem as preferên-

\footnotetext{
${ }^{7} \mathrm{O}$ texto em questão possui duas partes, a primeira consiste em uma espécie de "editorial" autorizado por Weber e os demais editores, enquanto a segunda é de autoria exclusiva do nosso autor.

${ }^{8}$ Weber separa aquilo que "é" daquilo que "deveria ser" e postula que a ciência social só pode objetivar aquilo que "é", dada a impossibilidade de compreensão e distinção dos melhores valores, ou seja, do "dever ser".
} 
cias subjetivas e as ideias de valor do pesquisador, não é possível selecionar o objeto, impossibilitando o conhecimento causal do real particular. $\mathrm{O}$ tipo ideal, por exemplo, é um ponto de vista que acentua aspectos unilaterais. Em poucas palavras, a objetividade do conhecimento nas ciências sociais está fundada em princípios subjetivos, o que, segundo o autor, não impede a explicação causal objetiva. Em "A Ciência como Vocação", uma forte crítica à militância política no ambiente acadêmico, o autor repete com maior ênfase alguns dos argumentos expostos acima. A partir de uma análise comparativa entre as condições do professor e do pesquisador acadêmico nos Estados Unidos e na Alemanha, Max Weber começa a conferência apontando os pontos externos que rodeiam a ciência como vocação, concentremo-nos na segunda parte do texto, referente às condições internas da ciência.

O autor parte da premissa de que a ciência, no sentido moderno, é um projeto sem fim, mas "a intelectualização e a racionalização crescentes não equivalem a um conhecimento geral crescente acerca das condições que vivemos" (WEBER, 2011, p. 35). Nada garante ao homem civilizado que seu conhecimento acerca da vida é maior que o de um hindu, exemplifica o autor. Se os indivíduos de comunidades pré-modernas podiam se sentir plenos da vida, ao ser humano "civilizado" sobrou apenas a possibilidade de sentir-se cansado da vida. Weber chamou esse processo de desencantamento do mundo ${ }^{10}$, em que substituímos os "meios mágicos" pela "técnica" e pela "previsão". Presos na ideia de progresso infinito, interpretamos a vida como algo sem sentido que captura apenas o provisório e nunca o definitivo (Weber, 2011).

Partindo de uma análise histórica, o autor apresenta um contraste entre a visão dos antigos e dos modernos acerca do significado da ciência. N'A República de Platão, o filósofo ou cientista é aquele que se liberta da caverna (da aparência, do mutável) para ir ao encontro do sol (a verdade, o eterno). Em tom irônico, Weber pergunta à plateia quem, "em nossos dias", é capaz de adotar uma perspectiva platônica sobre a ciência? Sua resposta é que em nosso tempo não há mais espaço para aquilo que ele identifica como um idealismo de Platão. É na "caverna" que se encontra o real, não há nada fora dela a não ser "fantasmas inanimados", apartados da realidade. No entanto, o sociólogo preocupa-se com a total descrença que assola a juventude de seu tempo ${ }^{11}$ e procura recuperar, de alguma forma, a objetividade do conhecimento. Segundo Weber, é nos gregos que encontramos o primeiro grande instrumento da ciência: o "conceito".

Acreditou-se possível concluir que bastava descobrir o verdadeiro conceito do Belo, do Bem ou, por exemplo, o da Coragem ou da Alma - ou de qualquer outro objeto - para ter condição de compreender-lhe o ser verdadeiro. Conhecimento que, por sua vez, permitiria saber e ensinar a forma de agir corretamente na vida e, antes de tudo, como cidadão (WEBER, 2011, p. 38).

No renascimento, continua o autor, descobre-se o segundo grande instrumento da ciência, "a experimentação racional". Por meio desse instrumento essencial à "ciência empírica moderna", os indivíduos acreditaram poder controlar a experiência de forma segura. A partir de homens como Bacon e Galileu a experimentação atingiu o status de "princípio da pesquisa", por meio da qual nos conduziríamos à apreensão da natureza. Novamente, como certa ironia, Weber questiona:

\footnotetext{
${ }^{9}$ Aqui, o autor distancia-se da herança neokantiana presente em Rickert. Em Weber, os valores perdem o status de "absolutos" que adquiriram com os historicistas neokantianos, conforme argumenta Raquel Weiss, (2012). Todavia, vale observar que Weber considera útil o princípio nomotético ou generalizante, i.e, formulação de leis gerais. De modo que não o restringe apenas às ciências naturais, como fizera a tradição neokantiana que herdara, mas faz uso dele como meio da ciência social, em conjunto com seu método compreensivo, e não como fim, no intuito de orientar a visão do pesquisador para certos aspectos da realidade que tendem a ser relevantes para o entendimento dos fenômenos sociais (Lobo, 2018).

${ }^{10}$ Cabe aqui lembrarmos da proximidade da tese weberiana com a interpretação nietzscheana da modernidade e o conceito de niilismo. Trataremos sobre isso ao final do trabalho.

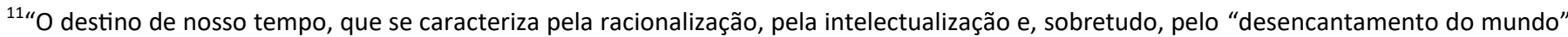
levou os homens a banirem da vida pública os valores supremos e sublimes" (WEBER, 2011, p. 62).
} 


\begin{abstract}
"Quem continua a acreditar - salvo algumas crianças - que os conhecimentos astronômicos, biológicos, físicos ou químicos poderiam ensinar-nos algo a propósito do sentido do mundo ou poderiam ajudar-nos a encontrar sinais de tal sentido, se é que ele existe?" (WEBER, 2011, p. 40).
\end{abstract}

A última dose de ironia para com aqueles que depositaram alguma esperança no potencial humano de encontrar o "sentido da vida" é direcionado ao "romantismo intelectualista irracional". Para Weber, "a técnica do domínio da vida fundamentada na ciência - como caminho que levará à felicidade" foi completamente destruída enquanto possibilidade pelos argumentos arrasadores de Nietzsche dirigidos aos confortáveis e felizes "últimos homens" (Ibidem, p. 40). Se, contudo, estão destruídas todas as ilusões e pretensões acerca da apreensão do "ser verdadeiro", da "verdadeira natureza, do "verdadeiro Deus" e da "verdadeira felicidade", qual é, enfim, "o sentido da ciência enquanto vocação"? (Ibidem, p. 42). Para responder essa questão precisaremos, como fez Weber, voltar ao problema dos valores.

Ao procurar uma saída para a afirmação de Tolstói de que a ciência não tem sentido pois não nos responde como devemos viver e o que devemos fazer - Weber procura distanciarse do "hábito de falar insistentemente numa 'ciência sem pressupostos'”, demonstrando que além de pressupor regras válidas da lógica e da metodologia, a ciência pressupõe também, a importância contida nos resultados das pesquisas. Em outras palavras, os cientistas, por motivos que escapam à demonstração cientifica, escolhem seus objetos "conforme as tomadas de posição pessoais definitivas, face à vida" (Ibidem, p. 42-3). Resta-nos aceitar ou recusar tais pressupostos, nunca os admitir enquanto portadores da verdade ou do bem em si apreensível de forma racional/científica. Não é possível provar a validade de um estudo de determinado objeto de forma objetiva, os critérios dos quais dispomos são inteiramente subjetivos, argumenta Weber. As "ciências históricas", por exemplo:
[...] nos capacitam a conhecer os fenômenos políticos, artísticos, literários e sociais da civilização a partir de suas condições de formação. Mas, não dão, por si mesmas, respostas à pergunta: esses fenômenos mereciam ou merecem existir? Elas pressupõem, simplesmente, que há interesse em tomar parte, pela prática desses conhecimentos, na comunidade dos "homens civilizados". Não podem, entretanto, provar "cientificamente" que haja vantagem nessa participação; e o fato de pressuporem tal vantagem não prova, de forma alguma, que ela exista. Em verdade, nada do que foi mencionado é, por si próprio, evidente. (WEBER, 2011, p. 45).

Ainda antes de responder a problemática sobre qual o sentido da ciência e qual sua contribuição para a vida prática, o autor continua a conferência expondo os limites da ciência e as razões práticas para que os cientistas não façam juízos de valor. Segundo Weber, a política está deslocada, pois não deveriam ter espaço na academia "o profeta e o demagogo". Há um grande risco de que o cientista, ao manifestar seus próprios juízos de valor na pesquisa ou na sala de aula, perca a "compreensão integral dos fatos". O autor chega a defender, enquanto atitude "moral" do professor, a demonstração do fato como ele é, por mais "desagradável" que ele pareça para as opiniões particulares (WEBER, 2011, p. 47-9).

Para além das razões práticas expostas acima, Weber assume que há motivos de outra ordem que obrigam o verdadeiro cientista a abrir mão de juízos de valor. Citando John Stuart Mill, Baudelaire e Nietzsche, o autor reivindica o "politeísmo" de valores e afirma que a "sabedoria popular nos ensina, enfim, que uma coisa pode ser verdadeira, conquanto não seja bela nem santa nem boa". Cada indivíduo decide de acordo com sua perspectiva "o que, para ele, é deus e o que é o diabo" (Ibidem, p. 49-51).

Voltemo-nos, finalmente, à tentativa weberiana de responder qual o sentido da ciência e de que maneira ela contribuí para a vida prática? Weber apresenta três de suas vantagens: em primeiro lugar, a ciência produz "conhecimentos que nos permitem dominar tecnicamente a vida por meio 
da previsão". Em segundo lugar, a ciência nos proporciona "métodos de pensamento, isto é, os instrumentos e uma disciplina". Por fim, a ciência contribui para a clareza (Ibidem, p. 54-5). Ou seja, frente a determinado problema de valor, o cientista pode demonstrar que é possível adotar determinadas posições. A ciência nos auxilia, portanto, a dar conta dos meios condizentes com determinado "sentido último" dos nossos atos:

A ciência mostrará que, adotando tal posição, certa pessoa estará a serviço de tal Deus e ofendendo tal outro e que, se se desejar manter fiel a si mesma, chegará, certamente, a determinadas consequências íntimas, últimas e significativas. Eis o que a ciência pode proporcionar, ao menos em princípio. Essa mesma obra é o que procuram realizar a disciplina especial que se intitula Filosofia e as metodologias próprias das outras disciplinas. (WEBER, 2011, p. 56).

Contudo, se quisermos saber qual o sentido que deve guiar nossas vidas ou "que deus que devemos seguir dentre os muitos que se combate", precisamos procurar um profeta ou um salvador, essas são tarefas da vida política, da religião e até mesmo da Filosofia, mas não da ciência, afirma Weber. O destino de nossa época, na visão do autor, é a indiferença em relação aos deuses e profetas, portanto, aqueles que não suportarem o pesado fardo dos limites do saber, podem optar pelo "sacrifício do intelecto" e agarrarem-se à fé. Tanto o homem fiel à probidade intelectual, quanto aquele que aposta na crença religiosa são superiores aos "profetas" catedráticos. Pois, nas palavras do autor, há "uma tensão invencível entre o domínio da crença na 'ciência' e o domínio da salvação religiosa" e "enquanto tentarmos fabricar intelectualmente novas religiões, chegaremos, em nosso íntimo, na ausência de qualquer nova e autêntica profecia, a algo semelhante e que terá, para nossa alma, efeitos ainda mais desastrosos" (WEBER, 2011, p. 60-3). Max Weber encerra a conferência $A$ ciência como vocação afirmando que seguir a vocação é simples e fácil, desde que, cada qual encontre e obedeça "ao demônio que tece as teias de sua vida" (Ibidem, p. 64).
Antes de iniciarmos a próxima seção do presente trabalho, cabe salientar dois argumentos expostos em dois outros textos do autor. Em "Estudos críticos sobre a lógica das ciências da cultura", Weber insurge-se contra a herança metafísica kantiana muito presente nos estudos históricos de seu tempo. Eduard Meyer, principal interlocutor do texto, defendia uma distinção qualitativa entre a pesquisa de natureza "histórica" e o trabalho científico, para Meyer, o acaso e o livre querer são categorias da análise histórica e os juízos de valor teriam validade objetiva desde que refletissem os ideais da Razão (Weiss, 2012). Weber, ao afirmar que tais posições ultrapassam o campo da ciência e adentram as especulações filosóficas, confronta o argumento central do historiador kantiano, postulando a isenção valorativa e a necessária neutralidade axiológica para o trabalho histórico de pretensões científicas, Weber escreve:

\begin{abstract}
Um "juízo de valor" atual sobre um objeto concreto ou o estabelecimento teórico de relações de valor "possíveis", com referência a este objeto, de modo algum significa que façamos uma subsunção deste sob um conceito genérico como, por exemplo, "carta de amor", "formação política", ou "fenômeno econômico". Pelo contrário, um "juízo de valor" significa que "tomo posição" de uma maneira concreta e determinada, em relação a um objeto na sua especificidade concreta, e as fontes subjetivas desta minha tomada de posição, dos meus "juízos de valor" a respeito, de modo algum são "conceitos", e, menos ainda "conceitos abstratos", mas, diferentemente, um "sentir" e "querer" inteiramente concretos, ou, por outro lado, em certas circunstâncias, eventualmente a consciência de um "dever ser" que é determinado e configurado concretamente por um "aqui e agora" (WEBER 1993, p. 183).
\end{abstract}

Raquel Weiss, ao interpretar o texto "O significado de 'neutralidade axiológica' das ciências sociológicas e econômicas", enfatiza a sutileza da justificativa weberiana para a neutralidade axiológica. Weber, ao distinguir o campo dos estudos Éticos (Filosofia Moral ou dos valores) da Sociologia (ciência dos valores), "não nega a existência de 
valores e tampouco defende uma posição relativista, nos moldes da escola histórica" ${ }^{12}$, no entanto, "atinge as bases da Filosofia Moral, cujo empreendimento sempre foi o de encontrar verdadeiros valores que deveriam nortear a ação humana" (WEISS, 2012, p. 128). Enfim, convicto de que há, na prática, um "politeísmo" de valores irreconciliável, Weber afirma que não é função da ciência defender determinada posição subjetiva, ou seja, determinado valor.

\section{A CRÍTICA STRAUSSIANA À DISTIN- ÇÃO ENTRE FATOS E VALORES}

Strauss via nas reflexões de Weber as grandes influências da ciência social e política de sua época, a qual caracterizava-se pela aceitação da impossibilidade de resolução dos conflitos entre valores através de instrumentos racionais e científicos ${ }^{13}$. Foi Weber quem postulou a distinção entre fatos e valores ao afirmar que cabe a ciência apenas pronunciar-se sobre fatos, fazendo referências, mas não julgamentos de valor. Portanto, é Weber quem Strauss elege como a principal influência do positivismo ${ }^{14}$ de sua época. A posição substancial de Weber, nas palavras de Strauss, passa pela suposição de que há "[...] uma variedade de princípios imutáveis do direito ou da bondade que conflitam uns com os outros sem que se possa provar a superioridade de nenhum deles" (STRAUSS, 2014, p. 45).

Strauss dedica-se a confrontar os argumentos de Weber durante todo o segundo capítulo de "Direito Natural e História" e no restante do livro, procura postular a possibilidade de retorno da ideia de direito natural na ciência social contempo- rânea, através de um esforço historiográfico sobre a gênese do direito natural proposta pelos gregos clássicos, as teorias do direito natural moderno e por fim, sua crise. $\mathrm{O}$ autor procura distinguir as diferenças entre a tese historicista, expostas no primeiro capítulo do livro, e a tese positivista de Weber. Os historicistas advogam que todo o pensamento humano é considerado histórico e contextual, portanto, também o é o direito natural, ainda que preserve certa pretensão objetiva dentro de determinado contexto. Weber, por sua vez, "opõese à escola histórica não por ter ela obscurecido a ideia de direito natural, mas por ter preservado o direito natural sob vestes históricas em vez de rejeitá-lo integralmente (Ibidem, p. 45).

Segundo Strauss, Weber foi fortemente influenciado pela ideia de ciência de seu tempo, pela noção de que a ciência moderna é superior a todas as outras formas de compreensão da sociedade. Embora ele tenha postulado que os valores são importantes para orientar a definição do objeto de pesquisa, a "heterogeneidade absoluta de fatos e valores" leva o sociólogo alemão a, inevitavelmente, apontar para a necessidade da neutralidade axiológica no trabalho científico. $O$ fundamento da noção weberiana de ciência, "eticamente neutra", apresenta-se de forma clara na distinção entre aquilo que "é" e aquilo que "deve ser", a chave do argumento está em negar a possibilidade de deliberar acerca do "dever ser". Se houvesse a possibilidade de apreensão do "dever ser", este guiaria a ciência social, no entanto, o que há é um conflito, pela razão humana, entre uma infinidade de valores $^{15}$. Em decorrência, Strauss afirma que a tese de Weber "leva necessariamente ao niilismo", pois, todas as preferências, por mais absurdas e cruéis

\footnotetext{
${ }^{12}$ Conforme argumenta Raquel Weiss: “Weber faz questão de ressaltar que esta sua posição não pode ser entendida como relativista, o que é um elemento importante inclusive para situá-lo no debate daquele momento. No âmbito do historicismo alemão, os partidários do relativismo sustentavam uma vinculação necessária entre os valores e os momentos singulares do curso histórico, sendo que os primeiros seriam fruto deste; portanto, os valores seriam considerados como válidos e verdadeiros para o período histórico em que foram gerados. A consequência desse tipo de argumento seria a de que cada momento histórico só poderia ter aqueles valores, e tais valores não poderiam valer em outro momento. Essa relação necessária eliminaria a possibilidade de liberdade da escolha humana. Essa tese foi defendida, dentre outros, por Spengler, no mesmo período em que Weber redigiu o texto em questão" (WEISS, 2012, p. 128)

${ }^{13}$ A ciência então pôde servir a qualquer coisa, qualquer governo, seja ele bom ou mal.

${ }^{14}$ Strauss usa o termo "positivismo" de modo sui generis. De fato, Strauss traça paralelo entre o positivismo de Comte e Weber, mas também observa divergências, sobretudo, porque entre Comte e Weber existe a crítica nietzscheana ao ideal da razão positivista. 0 uso parece ser feito de forma estratégica, pois Weber exerce forte influência na ciência empírica dominante no contexto americano da década de 1950, inclusive em Chicago, onde David Easton era o professor mais proeminente.
} 
que pareçam ser, são tão legítimas quanto quaisquer outras. E exemplifica:

\begin{abstract}
Um sinal inequívoco dessa necessidade é dado por uma formulação de Weber sobre as perspectivas futuras da civilização ocidental. Ele viu a seguinte alternativa: ou uma renovação espiritual ("profetas inteiramente novos ou um poderoso renascimento de pensamentos e ideias antigos"), ou então uma "petrificação mecanizada, lustrada por um tipo de vaidade convulsiva, isto é, a extinção de toda possibilidade humana exceto de "especialistas sem alma nem visão e de voluptuosos sem coração". Diante dessas alternativas, Weber percebeu que a decisão a favor de uma ou outra possibilidade corresponderia a um juízo de valor e de fé e ultrapassaria, portanto, a competência da razão (STRAUSS, 2014, p. 51-2).
\end{abstract}

Weber acreditou que o "desencantamento" caracterizava a sociedade na qual ele vivia, e, preocupava-lhe o fato de que só a fé possibilitava a dedicação a causas ou ideias. Portanto, afirma Strauss, "ele se viu confrontado com a alternativa de um esvaziamento espiritual absoluto ou uma restauração religiosa" (Ibidem, p. 89). Na perspectiva straussiana, Weber teria se deparado com o problema fundamental das sociedades ocidentais desde a Grécia Antiga, o conflito entre a razão e a religião.

No entanto, sua pretensa neutralidade axiológica o impediu de ajuizar sobre as alternativas na visão de Strauss, também fundamentais - para o problema, pois, fazê-lo seria tomar lado entre os partidos. Apesar de rejeitar aquilo que foi postulado por toda a tradição da filosofia, de Platão a Hegel, "Weber nunca explicou o que entendia por 'valores'" (ibidem, p. 44). O sociólogo alemão, que "escreveu milhares de páginas", dedicou "pouco mais de trinta" para o tema que constitui a "base que compreenderia a totalidade de seu posicionamento". O que sugere, sob essa perspectiva, que o postulado weberiano pode não ser fundamentado empiricamente, sendo assim, uma premissa feita sob uma "preferência moral específica", diz Strauss (Ibidem, p. 77). Ou seja, a distinção entre fatos e valores em Weber, não está baseada em uma tese lógica ou metodológica, mas axiológica. Nas palavras de Strauss, o "sacrifício do intelecto" postulado por Weber, "um sacrifício abominado pela ciência ou filosofia, está na raiz da ciência ou filosofia". Pois, a ciência é incapaz de justificar-se de forma racional, ela é o resultado de um processo contingente e histórico e, assim como qualquer outro conjunto de crenças que a sucedeu, ela não é uma necessidade.

A questão que importa para Leo Strauss é se o ser humano pode adquirir o discernimento sobre o bem e o mal, o certo e o errado, por meio da razão desassistida, ou, se é necessário a orientação divina. Strauss indica que além da opção religiosa, durante toda a tradição da filosofia ocidental, sempre se acreditou em outra alternativa: a orientação humana. Essas duas alternativas não são passiveis de "harmonização ou síntese", argumenta o autor. Sempre que há essa tentativa, um dos dois elementos é sacrificado ${ }^{16}$, pois ambas postulam que apenas uma única coisa importa: "a vida de amor e obediência para uma, e a vida da liberdade do conhecimento, para outra" (STRAUSS, 2014 , p. 89-90). Strauss sugere que Weber, preso por um "traço de seu caráter" optou pela "honestidade intelectual". No entanto, se admitirmos que buscar racionalmente a verdade é considerado tão legítimo quanto sacrificar o intelecto "em favor do belo ou do sagrado", por que não poderíamos preferir as "ilusões agradáveis ou os mitos edificantes"? Pergunta retoricamente

\footnotetext{
${ }^{15}$ Nas palavras de Weber, "a vida, enquanto encerra em si mesma um sentido e enquanto se compreende por si mesma, só conhece o combate eterno que os deuses travam entre si ou - evitando a metáfora - só conhece a incompatibilidade das atitudes últimas possíveis, a impossibilidade de dirimir seus conflitos e, consequentemente, a necessidade de decidir em prol de um ou de outro" (2011, p. 59)

${ }^{16}$ A escolástica por um lado e o movimento iluminista por outro parecem ser os exemplos paradigmáticos de cada uma dessas tentativas de síntese. Strauss sugere uma terceira via à luz do racionalismo clássico pré-moderno, que, ciente desse conflito irresolvível entre a razão (ciência, filosofia) e a cidade (convenções, política, religião), procuravam de forma prudente introduzir ensinamentos edificantes ("belos mitos", "nobres mentiras") para os homens da cidade, preservando ao mesmo tempo a coesão social e a possibilidade da filosofia. Na nossa interpretação, o direito natural caminha nessa direção. Essa temática pontua toda a obra do autor, mas para uma síntese do argumento, ver: "The city and man", Strauss, 1992 (1964).
} 
Strauss ao indicar a possibilidade de transcender o niilismo weberiano distinguindo aquilo que é nobre daquilo que é baixo. (Ibidem, 58-9) ${ }^{17}$.

\section{UMA CIÊNCIA SOCIAL PORVIR}

Ao criticar a concepção de Weber sobre a realidade, uma concepção que ele herdara do neokantismo "modificando-a ligeiramente pelo acréscimo de um ou dois traços emocionais", Strauss encerra o capítulo apontando as bases necessárias para uma ciência social valorativa. Para Weber, segundo Strauss, a realidade é uma "sucessão infinita e sem sentido", "um caos de acontecimentos singulares". No entanto, nem o próprio sociólogo alemão teria aderido coerentemente a essa concepção, ele não negou que há uma compreensão da realidade que precede a concepção científica.

[...] qual seja: a expressão e riqueza de sentido que temos em mente quando falamos do mundo da experiência comum ou da compreensão natural do mundo. Mas ele sequer arriscou uma análise coerente do mundo social tal como entendido pelo "senso comum", ou da realidade social que se conhece no dia a dia. $\mathrm{O}$ lugar dessa análise está ocupado na sua obra pela definição de tipos ideias, de constructos artificiais que sequer pretendem corresponder à expressão intrínseca da realidade social e que pretendem ter, aliás, um caráter estritamente efêmero (STRAUSS, 2014, p. 93).

Apenas partindo do "senso comum", como faziam os filósofos clássicos ${ }^{18}$, poderíamos dar conta de uma ciência social valorativa, só assim, a interpretação "tornaria inteligível as alternativas fundamentais que pertencem essencialmente à vida social". Fornecendo, portanto, as bases para julgar a possibilidade de resolução do conflito entre essas alternativas. Weber, na perspectiva straussiana, negou-se a solucionar a crise de seu tempo, pois seguiu o espírito do pensamento moderno que sob forte influência da "nova física" rompe com a filosofia política clássica e passa a distinguir "ciência" de "filosofia", sendo que a primeira adquire autoridade sobre a segunda.

Nasser Behnegar, professor do departamento de Ciência Política da Boston College, dedicou-se a estudar o debate entre Leo Strauss e Max Weber a respeito do que ele chamou de busca por uma Ciência Social Genuína ${ }^{19}$. Para o intérprete, Strauss preocupa-se com as consequências teóricas e práticas de Weber, aceitou sua tese pois acreditou que ela leva necessariamente à tolerância (pois a ciência social democracia) e ao conhecimento genuíno. No entanto, Strauss procurou mostrar que o relativismo não leva necessariamente à tolerância, pelo contrário, ao insurgir-se contra todo absolutismo ele transforma-se também em dogmatismo, rechaçando a priori qualquer tentativa contrária à premissa relativista. Na concepção de Strauss, o relativismo representava para o mundo contemporâneo um mal maior que o absolutismo, portanto, suas críticas mais árduas são endereçadas a ele, diz Behnegar (1997). Contudo, sua intenção é libertar o pensamento de ambas as formas de dogmatismo, propondo um retorno ao ceticismo clássico - o racionalismo zeetético (investigativo) - presente no pensamento grego pelo menos desde a máxima socrática "só sei que nada sei". Strauss insurge-se como contraponto ao que ele considerava o filisteísmo acadêmico, em partes, decorrente do nilismo weberiano. Uma virada nas Humanidades que, na sua perspectiva, mostra-se intolerante quando se pretende inclusiva.

\footnotetext{
17 O tema platônico das "nobres mentiras", direcionadas ao vulgo enquanto ensinamentos exotéricos, é crucial no pensamento de Leo Strauss. Se, para os iniciados na vida filosófica, as "verdades mortais" devem ser expostas, para a sociedade como um todo elas são permissivas e desagregadoras. Na visão de Strauss, falta aos pensadores modernos responsabilidade e prudência no que diz respeito às "verdades mortais", isso ocorre em função do esquecimento da antiga arte de escrever que distinguia nas entrelinhas dos textos a escrita esotérica (para os iniciados) da escrita exotérica (para o vulgo). Para Strauss, a posição moderna se levada às últimas consequências produz o niilismo. Sobre esse tema, ver: (Strauss, 2015 (1952); Melzer 2014 e Silva, 2019).

${ }^{18}$ Strauss propõe um retorno às bases da filosofia ocidental, ao modo como os clássicos operavam ao fazer Filosofia Política, conforme o terceiro e quarto capítulo de "Direito Natural e História", intitulados "A origem do Direito Natural" e "O direito Natural Clássico". Ver também os ensaios "O que é Filosofia Política?" e "Sobre a Filosofia Política Clássica" (Strauss, 2016 [1989]).

${ }^{19}$ A tese está exposta no artigo "Leo Strauss's Confrontation with Max Weber: A Search for a Genuine Social Science" (1997). Behnegar é também autor de um livro sobre o tema "Leo Strauss, Max Weber, and the Scientific Study of Politics" (2003).
} 
Diante do conflito entre ciência e religião, Weber angustiou-se ao perceber que a ciência estava fundada na negação da razão e que, portanto, sofria de uma fraqueza fatal. Strauss, por outro lado, acreditou que a filosofia clássica, enquanto modo de vida, possuía uma resposta para essa dificuldade (BEHNEGAR, 1997, p. 125). Behnegar chega a sugerir, que na visão de Strauss, o conflito é passível de solução através do resgate da ideia de Direito Natural.

\section{REFERÊNCIAS}

BEHNEGAR, Nasser. Leo Strauss's Confrontation with Max Weber: A Search for a Genuine Social Science. The Review of Politics, Notredame, v. 59, n. 1, p. 97-125, 1997.

BEHNEGAR, Nasser. Leo Strauss, Max Weber, and the Scientific Study of Politics. Chicago: University of Chicago Press, 2003.

GOUREVITCH, V. The Problem of Natural Right and the Fundamental Alternatives in Natural Right and History. In: The crisis of liberal democracy: a straussian perspective. Org. DEUTSCH, K. New York: State University of New York Press. PP. 3047. 1987.

LOBO, I. A contribuição neokantiana para a fundação das ciências sociais. Em Tese, Florianópolis, v. 15. n. 2, p.57-68, 2018.

MELZER, Arthur M. Philosophy between the lines: the lost history of esoteric writing. Chicago: The University of Chicago Press, 2014.

SILVA, Igor C. Leo Strauss entre a história da filosofia política e a filosofia política da história. Florianópolis: UFSC, 2019.

STRAUSS, Leo. Direito Natural e História. São Paulo: Editora Martins Fontes, 2014.

STRAUSS, Leo. Uma introdução à filosofia política: dez ensaios. São Paulo: É Realizações, 2016.

STRAUSS, Leo. Perseguição e a Arte de Escrever. São Paulo: É Realizações, 2015.

STRAUSS, Leo. The City and Man. Chicago: The University of Chicago Press, 1992.

WEBER, Max. Ciência e Política: Duas Vocações. São Paulo: Cultrix, 2011.

WEBER, Max. Metodologia das Ciências Sociais: Parte 1. Tradução: Augustin Wernet. São Paulo: Cortez Editora, 1993.

WEBER, Max. Metodologia das Ciências Sociais: Parte 2. Tradução: Augustin Wernet.. São Paulo: Cortez Editora, 1995.

WEISS, Raquel. Max Weber e o problema dos valores: as justificativas para a neutralidade axiológica. Revista Sociologia Política, Curitiba, v. 22, n. 49, p. 113-137, março 2013. 